\title{
Algoritma Apriori Sebagai Solusi Kontrol Persediaan Suku Cadang Mobil PT. Buanasakti Aneka Motor Jakarta
}

\author{
Normah $^{1}$, Bakhtiar Rifai ${ }^{2}$, Pita Sari ${ }^{2}$ \\ ${ }^{1}$ Sekolah Tinggi Manajemen Informatika dan Komputer Nusa Mandiri/Teknik Informatika \\ e-mail: normah.nor@nusamandiri.ac.id \\ ${ }^{2}$ Sekolah Tinggi Manajemen Informatika dan Komputer Nusa Mandiri/Teknik Informatika \\ e-mail: bakhtiar.bri@nusamandiri.ac.id \\ ${ }^{3}$ Sekolah Tinggi Manajemen Informatika dan Komputer Nusa Mandiri/Sistem Informasi \\ e-mail: pitasari1111@nusamandiri.ac.id
}

\begin{abstract}
PT. BuanaSakti Aneka Motor is one of the car distributor agents located at warung buncit raya street No. 109 Duren Tiga, South Jakarta. Everyday the data piles is increase more and longer. PT. BuanaSakti Aneka Motor sometimes has difficulty to knowing how many spare parts occur in one transaction, so data or new stock information is difficult to find sometimes experiencing errors. To find out which products have the most sales and how they relate to one another, a priori algorithm method and the help of Rapidminer Tools are needed to produce associative rules. From the results of the discussion and analysis of the data it can be concluded that the application of a priori algorithm in determining the combination of itemset with a minimum support of $25 \%$ and a minimum of $60 \%$ confidence found 3 association rules, where the highest value of support and confidence is a radiator with a minimum stop lamp support of $26.92 \%$ while the minimum confidence is $64.65 \%$ and the oil filter with the minimum stop light support is $35.32 \%$ while the minimum confidence is $61.58 \%$, while lampu stop with head lamp minimum support 27,27\% and minimum confidence 69,03\%.
\end{abstract}

Keywords: Apriori Algorithm, Association Rules, Inventory, Car Parts

\begin{abstract}
Abstrak - PT. BuanaSakti Aneka Motor adalah salah satu agen distributor mobil yang berada di Jalan warung buncit raya No. 109 Duren Tiga Jakarta Selatan. Setiap hari banyaknya tumpukan data yang semakin lama akan semakin bertambah banyak. PT.BuanaSakti Aneka Motor terkadang mengalami kesulitan untuk mengetahui seberapa banyak suku cadang yang terjadi dalam satu transaksi, sehingga data atau informasi stock baru sulit dicari terkadang mengalami kekeliruan. Untuk mengetahui produk dengan penjualan terbanyak dan keterkaitan produk satu dengan yang lainnya, diperlukan metode algoritma apriori dan bantuan Tools Rapidminer untuk menghasilkan rules atau aturan asosiatif. Dari hasil pembahasan dan analisis data yang dilakukan dapat disimpulkan bahwa penerapan algoritma apriori dalam menentukan kombinasi antar itemset dengan minimum support $25 \%$ dan minimum confidence $60 \%$ ditemukan 3 aturan asosiasi, dimana nilai support dan confidence tertinggi adalah radiator dengan lampu stop minimum support 26,92\% sedangkan minimum confidence $64,65 \%$ dan oil filter dengan lampu stop minimum support 35,32\% sedangkan minimum confidence $61,58 \%$, sedangkan lampu stop dengan head lamp minimum support $27,27 \%$ dan minimum confidence $69,03 \%$.
\end{abstract}

Keywords: Algoritma Apriori, Aturan Asosiasi, Persediaan Suku Cadang Mobil

\section{PENDAHULUAN}

Perkembangan otomotif di Indonesia mengalami kemajuan yang sangat pesat salah satunya mobil. Dengan persaingan harga produk di pasaran membuat respon positif konsumen untuk membeli suku cadang mobil pada PT. BuanaSakti Aneka Motor yang merupakan perusahaan agen distributor mobil di Jalan warung buncit raya No. 109 Duren Tiga Jakarta Selatan.
Pengiriman barang sparepart harus tepat waktu, karena untuk menjaga kepercayaan konsumen atau toko tersebut. Diperlukan komunikasi antar distributor ke toko atau bengkel untuk menjalin informasi yang lebih baik agar tidak adanya kesalahan dalam pengiriman. Oleh karena itu kontrol stok persediaan sangatlah diperlukan, bagaimana menjaga agar produk terlaris selalu dalam keadaan ready stok, bagaimana meningkatkan penjulan untuk produk yang kurang laku terjual, menimimalisir barang-barang sparepart yang cacat atau retur agar 
tidak menjadi stock digudang. Permasalahan yang saat ini dihadapi adalah tidak mengetahui pola pelanggan dalam membeli sparepart dalam waktu bersamaan.

Dengan adanya kegiatan penjualan setiap hari banyaknya tumpukan data yang semakin lama akan semakin bertambah banyak. Kumpulan data tersebut dapat digunakan untuk menghasilkan informasi yang bermanfaat yang dapat diolah untuk pengambilan suatu keputusan. Pengolahan data tersebut bisa dilakukan dengan menggunakan teknik-teknik tertentu.

Menurut (Muflikhah et al., 2018), Asal mula data mining berasal dari irisan berbagai disiplin ilmu pengetahuan, yang meliputi: machine learning atau pattern recognition, statistik/kecerdasan buatan, dan sistem basis data. Hal ini disebabkan karena cara tradisional yang tidak sesuai untuk data yang amat besar, data dengan banyak dimensi, dan data yang heterogen dan tersebar. Menurut (Nofriansyah, 2014), Association Rule Mining adalah teknik data mining untuk menemukan aturan asosiatif antara suatu kombinasi item. Contoh aturan asosiatif dari analisis pembelian disuatu pasar swalayan adalah dapat diketahuinya berapa besar kemungkinan seorang pelanggan membeli roti bersamaan dengan susu.

Salah satu teknik yang digunakan dalam pengolahan data tersebut adalah dengan menggunakan metode algoritma apriori. "Algoritma asosiasi merupakan suatu bentuk algoritma dalam data mining yang memberikan informasi hubungan antar item data didatabase. Algoritma tersebut dapat dimanfaatkan secara luas dalam proses bisnis diantaranya dalam proses penjualan" (Badrul, 2016). Menurut (Muhammad et al., 2018), Rapidminer adalah platform perangkat lunak data ilmu pengetahuanyang dikembangkan oleh perusahaan dengan nama yang sama, yang menyediakan lingkungan terpadu untuk pembelajaran mesin (machine learning), pembelajaran mendalam (deep learning), penambangan teks (text mining), dan analisis prediktif (predictive analytics). Aplikasi ini digunakan untuk aplikasi bisnis dan komersial serta untuk penelitian, pendidikan, pelatihan, pembuatan prototype dengan cepat, dan pengembangan aplikasi serta mendukung semua langkah proses pembelajaran mesin termasuk persiapan data, visualisasi hasil, validasi dan pengoptimalan. Rapidminer dikembangkan dengan model open core.

Penelitian ini menerapkan data mining dengan menggunakan metode algoritma apriori sebagai solusi kontrol persediaan suku cadang mobil PT. Buanasakti Aneka Motor Jakarta. Beberapa masalah yang terjadi yaitu dengan banyaknya item kode suku cadang kendaraan sering terjadi kesalahan dalam pendataan stok persediaan barang, sulitnya pencarian data stok dan riwayat data penjualan sparepart karena terlalu banyaknya arsip, serta pendataan hanya menggunakan microsoft excel sehingga menyebabkan miss communication dalam memberikan info persediaan dan menghambat transaksi penjualan, pengiriman barang. Tujuan penelitian ini adalah membantu manager untuk mengetahui barang dan jenis-jenis sparepart yang mana saja yang paling banyak dan kurang laku terjual, sehingga dapat dilakukannya kontrol stok persediaan suku cadang mobil, serta membantu perusahaan dalam pengembangkan strategi pemasaran.

Penelitian tentang pola pembelian produk yang dilakukan komsumen (Santoso et al., 2016) terdapat masalah peletakkan barang-barang yang tidak sesuai dengan perilaku konsumen dalam membeli barang secara bersamaan dalam satu waktu. Hal ini tentu akan mempengaruhi tingkat penjualan barang. Maka diperlukan adanya aplikasi untuk mengelompokkan data barang berdasarkan kecenderungannya yang muncul bersamaan dalam suatu transaksi menggunakan metode Algoritma Apriori. Hasil dari penelitian ini alat bantu keputusan dalam menentukan penempatan barang diarea yang saling berdekatan sesuai prilaku konsumen dalam membeli barang secara bersamaan dan mempermudah konsumen dalam membeli produk yang saling berkaitan dengan nilai support 2 dan minimum confidence $60 \%$.

Dalam penelitian (Saputra et al., 2016) selama ini data dari penjualan pada delta motor hanya digunakan untuk rekap penjualan dan arsip. Padahal data tersebut dapat digunakan pemilik untuk pengembangan strategi pemasaran. Agar mempermudah analisis data dan membantu memberikan informasi data penjualan diperlukan metode Apriori guna memberikan solusi kepada pemilik untuk meningkatkan bisnis perusahaan. Hasil yang diperoleh adalah hubungan relasional antar tiap produk yang dibeli secara bersamaan dapat dirumuskan mengguakan analisa asosiasi. Nilai support 3 dan confidence $45 \%$ akan mempunyai keterikatan yang sama.

Dalam penelitian (Ummi, 2016) saat stok suku cadang yang jumlahnya tinggal sedikit, kantor hanya meminta kiriman stok suku cadang tersebut dari pusat tanpa mengetahui suku cadang lain yang jika suku cadang tersebut dibeli maka suku cadang yang lain juga dibeli. Hal ini mempersulit pada saat penyetokan barang karena banyak jenis dari suku cadang mobil. Untuk mengatasi permasalahan tersebuk PT IDK menerapkan metode Algoritma Apriori untuk memberikan rekomendasi penyetokan barang dan mempermudah penataan barang yang saling ketergantungan. Hasil dari penelitian ini 
proses penentuan pola penjualan dapat dilakukan dengan melihat hasil dari kecenderungan konsumen berdasarkan 2 itemset dengan nilai minimum support $50 \%$ dan minimum confidence $70 \%$. Dan perusahaan dapat mengatur letak posisi dari sparepart secara berdekatan.

\section{METODOLOGI PENELITIAN}

Tahapan dalam penelitian ini sebagai berikut:

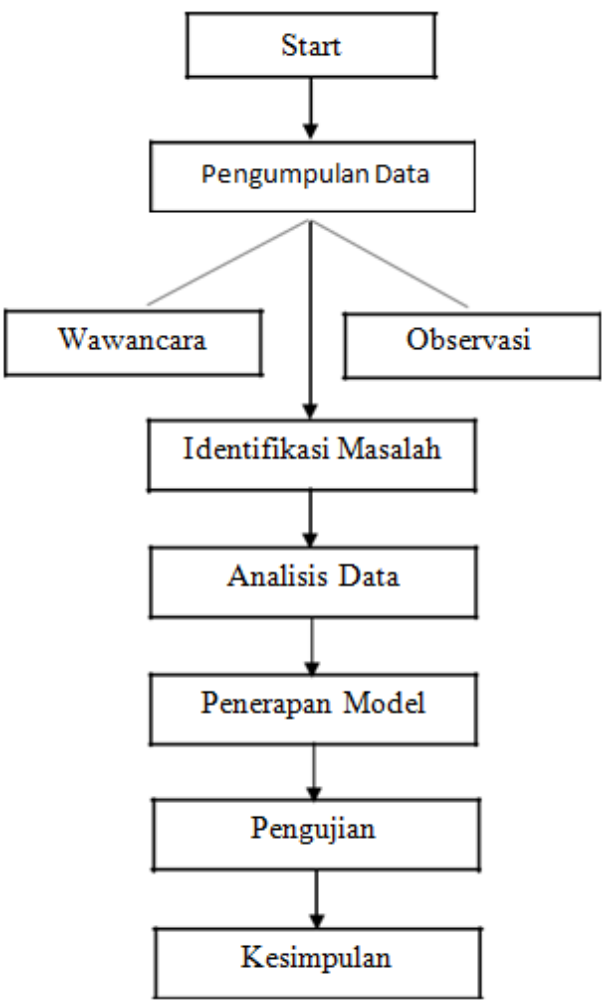

Gambar 1. Tahapan Penelitian

Data yang diambil yaitu data penjualan sparepart mobil pada PT. Buanasakti Aneka Motor dari tanggal 2 januari 2019 s/d 29 maret 2019 dengan jumlah sample sebanyak 19 produk suku cadang mobil, menggunakan metode Apriori sebagai berikut:

\section{Analisis pola frekuensi tinggi}

Tahap ini mencari kombinasi item yang memenuhi syarat minimum dari nilai support dalam database, menggunakan rumus (Nofriansyah, 2014):

Support $=$

$(A \cap B)=\frac{\sum \text { Transaksi yang mengandung } A \text { dan } B}{\sum \text { Transakasi }} * 100 \%$

\section{Pembentukan aturan asosiatif}

Setelah semua pola frekuensi tinggi ditemukan, barulah dicari aturan asosiatif yang memenuhi syarat minimum untuk confidence dengan menghitung confidence aturan asosiatif $\mathrm{A} \rightarrow \mathrm{B}$ dengan menggunakan rumus (Nofriansyah, 2014):

Confidence $=$

$\frac{\sum \text { Transaksi yang mengandung A dan } B}{\sum \text { Transakasi mengandung } A} * 100 \%$

\section{HASIL DAN PEMBAHASAN}

Pada PT BuanaSakti Aneka Motor terdapat beberapa permasalahan yang kerap muncul mengenai persediaan suku cadang mobil. Dengan banyaknya item kode suku cadang kendaraan sering terjadi kesalahan dalam pendataan stok persediaan barang, sulitnya pencarian data stok dan riwayat data penjualan sparepart karena terlalu banyaknya arsip, serta pendataan hanya menggunakan microsoft excel sehingga menyebabkan miss communication dalam memberikan info persediaan dan menghambat transaksi penjualan, pengiriman barang.

Dengan algoritma apriori, penentuan pola penjualan dapat dilakukan dengan melihat hasil dari kecenderungan pembelian konsumen dapat membantu manager untuk mengetahui barang dan jenis-jenis suku cadang/sparepart yang mana saja yang paling banyak dan kurang laku terjual, sehingga dapat dilakukannya kontrol stok persediaan suku cadang mobil, serta membantu perusahaan dalam pengembangkan strategi pemasaran. Tabel 1 berikut merupakan daftar penjualan.

\begin{tabular}{ll}
\multicolumn{2}{c}{ Table 1. Sample Produk Sparepart } \\
\hline NO & Nama Suku Cadang Mobil \\
\hline $\mathbf{1}$ & Bemper BLK \\
$\mathbf{2}$ & Bemper DPN \\
$\mathbf{3}$ & Lampu Stop \\
$\mathbf{4}$ & Headlamp \\
$\mathbf{5}$ & Panel Bagasi \\
$\mathbf{6}$ & Radiator \\
$\mathbf{7}$ & Air Filter \\
$\mathbf{8}$ & Oil Filter \\
$\mathbf{9}$ & Kap Motor \\
$\mathbf{1 0}$ & Bullhead \\
$\mathbf{1 1}$ & Balljoint \\
$\mathbf{1 2}$ & Grille Bemper \\
$\mathbf{1 3}$ & Shockbreker DPN \\
$\mathbf{1 4}$ & Shockbreker BLK \\
$\mathbf{1 5}$ & List Kaca DPN \\
$\mathbf{1 6}$ & List Kaca BLK \\
\hline &
\end{tabular}




\begin{tabular}{ll}
\hline $\mathbf{1 7}$ & Kaca DPN \\
$\mathbf{1 8}$ & Kaca BLK \\
$\mathbf{1 9}$ & Tutup Tabung Air Radiator \\
\hline
\end{tabular}

Table 2. Riwayat Transaksi Penjualan Suku Cadang Mobil PT. Buanasakti Aneka Motor Jakarta

\begin{tabular}{|c|c|c|c|}
\hline No & Tgl & $\begin{array}{c}\text { Nama } \\
\text { Bengkel }\end{array}$ & Nama Sparepart \\
\hline 1 & $\begin{array}{c}02- \\
\text { Jan- } \\
19\end{array}$ & $\begin{array}{l}\text { New Jaya } \\
\text { Agung }\end{array}$ & $\begin{array}{l}\text { Air Filter, Shockbreker } \\
\text { Blk, Balljoint, } \\
\text { Shockbreker Dpn, Tutup } \\
\text { Tabung Air Radiator, } \\
\text { Oil Filter, Bull Head, } \\
\text { Bemper Dpn, Lampu } \\
\text { Stop, Headlamp }\end{array}$ \\
\hline 2 & & $\begin{array}{l}\text { Karunia } \\
\text { Utama }\end{array}$ & $\begin{array}{l}\text { Radiator, Shockbreker } \\
\text { Blk, Oil Filter, List } \\
\text { Kaca Dpn, Lampu Stop, } \\
\text { Headlamp }\end{array}$ \\
\hline 3 & & $\begin{array}{l}\text { Prima } \\
\text { utama } \\
\text { Motor }\end{array}$ & $\begin{array}{l}\text { Air Filter, Oil Filter, } \\
\text { Lampu Stop, Headlamp, } \\
\text { Kaca Blk }\end{array}$ \\
\hline 4 & & Cash & $\begin{array}{l}\text { Air Filter, Oil Filter, } \\
\text { Bull Head, Balljoint, } \\
\text { Lampu Stop, Headlamp, } \\
\text { Shockbreker Dpn }\end{array}$ \\
\hline 5 & & Harvest & $\begin{array}{l}\text { List Kaca Blk, Balljoint, } \\
\text { Radiator, Shockbreker } \\
\text { Blk, Tutup Tabung Air } \\
\text { Radiator, Bull Head, } \\
\text { Oil Filter, Shockbreker } \\
\text { Dpn }\end{array}$ \\
\hline 6 & & $\begin{array}{l}\text { Ekky } \\
\text { Motor }\end{array}$ & $\begin{array}{l}\text { Balljoint, Bemper Blk, } \\
\text { Lampu Stop, Oil Filter, } \\
\text { Shockbreker Dpn }\end{array}$ \\
\hline$\cdots \cdots$ & & & \\
\hline 118 & $\begin{array}{l}01- \\
\text { Feb- }\end{array}$ & $\begin{array}{l}\text { Agung } \\
\text { Mandiri }\end{array}$ & $\begin{array}{l}\text { List Kaca Dpn, Kaca } \\
\text { Dpn, Grile Bemper }\end{array}$ \\
\hline 119 & 19 & $\begin{array}{l}\text { Nusantara } \\
\text { Utara } \\
\text { Mandiri }\end{array}$ & $\begin{array}{l}\text { Lampu Stop, Bemper } \\
\text { Dpn, List Kaca Dpn, } \\
\text { Kaca Blk, Radiator }\end{array}$ \\
\hline 120 & & $\begin{array}{l}\text { New Jaya } \\
\text { Agung }\end{array}$ & $\begin{array}{l}\text { Shockbreker Blk, Oil } \\
\text { Filter, Air Filter, } \\
\text { Shockbreker } \\
\text { Radiator }\end{array}$ \\
\hline 121 & & $\begin{array}{l}\text { New Jaya } \\
\text { Agung } \\
\text { Motor }\end{array}$ & $\begin{array}{l}\text { Head Lamp, Bemper } \\
\text { Blk, Radiator }\end{array}$ \\
\hline 122 & & & $\begin{array}{l}\text { Shockbreker Blk, Oil } \\
\text { Filter, Shockbreker Dpn, } \\
\text { Lampu Stop, Radiator }\end{array}$ \\
\hline 123 & & Harvest & $\begin{array}{l}\text { Air Filter, Balljoint, } \\
\text { Lampu Stop, Radiator }\end{array}$ \\
\hline ..... & & . & $\ldots \ldots \ldots \ldots \ldots$ \\
\hline$\cdots \cdots$ & $\ldots \ldots$ & & \\
\hline 276 & $\begin{array}{l}28- \\
\text { Mar- } \\
19\end{array}$ & $\begin{array}{l}\text { PT. } \\
\text { Asuransi } \\
\text { Allianz }\end{array}$ & $\begin{array}{l}\text { List Kaca Blk, Balljoint, } \\
\text { Radiator, Shockbreker } \\
\text { Blk, Bemper Dpn, Air } \\
\text { Filter }\end{array}$ \\
\hline 277 & & $\begin{array}{l}\text { Padimas } \\
\text { motor }\end{array}$ & $\begin{array}{l}\text { Headlamp, } \\
\text { Tabung Air } \quad \text { Radiator, }\end{array}$ \\
\hline
\end{tabular}

\begin{tabular}{|c|c|c|c|}
\hline & & & $\begin{array}{l}\text { Bemper Blk, Bemper } \\
\text { Dpn, Air Filter }\end{array}$ \\
\hline 278 & & $\begin{array}{l}\text { ayun jaya } \\
\text { motor }\end{array}$ & $\begin{array}{l}\text { Shockbreker Blk, Kap } \\
\text { Motor, Kaca Dpn, Kaca } \\
\text { Blk, Bemper Blk, Air } \\
\text { Filter, Shockbreker Dpn, } \\
\text { Grile Bemper }\end{array}$ \\
\hline 279 & & $\begin{array}{l}\text { Seno } \\
\text { Motor }\end{array}$ & $\begin{array}{l}\text { Air Filter, Balljoint, } \\
\text { Lampu } \\
\text { Shockbreker Dpn }\end{array}$ \\
\hline 280 & & 8 selindo & $\begin{array}{l}\text { Oil Filter, Air Filter, } \\
\text { Balljoint, Kap Motor }\end{array}$ \\
\hline 281 & & $\begin{array}{l}\text { putra } \\
\text { wijaya }\end{array}$ & $\begin{array}{l}\text { Radiator, Lampu Stop, } \\
\text { Oil Filter, Kaca Dpn }\end{array}$ \\
\hline 282 & $\begin{array}{l}29- \\
\text { Mar- } \\
19\end{array}$ & $\begin{array}{l}\text { garasi } \\
\text { motor }\end{array}$ & $\begin{array}{l}\text { List Kaca Dpn, Bemper } \\
\text { Blk, Balljoint, } \\
\text { Headlamp, Kaca Blk }\end{array}$ \\
\hline 283 & & $\begin{array}{l}\text { nova } \\
\text { motor }\end{array}$ & $\begin{array}{l}\text { Kap Motor, Bemper Blk, } \\
\text { List Kaca Blk, Balljoint, } \\
\text { Headlamp, Shockbreker } \\
\text { Dpn }\end{array}$ \\
\hline 284 & & $\begin{array}{l}\text { klinik } \\
\text { pasar } \\
\text { minggu }\end{array}$ & $\begin{array}{l}\text { Shockbreker Blk, Oil } \\
\text { Filter, Bemper Dp, } \\
\text { Radiator, Bemper Blk, } \\
\text { Headlamp }\end{array}$ \\
\hline 285 & & inti auto & $\begin{array}{l}\text { Kaca Dpn, Air Filter, } \\
\text { Balljoint, Bemper Dpn, } \\
\text { Bemper Blk, Headlamp }\end{array}$ \\
\hline 286 & & $\begin{array}{l}\text { Lido } \\
\text { motor }\end{array}$ & $\begin{array}{l}\text { Shockbreker } \\
\text { Shockbreker Dpn, Oil } \\
\text { Filter, Bemper Blk, } \\
\text { Headlamp, Kaca Blk }\end{array}$ \\
\hline
\end{tabular}

Tabel 2 diatas merupakan daftar riwayat transaksi penjualan suku cadang mobil PT. Buanasakti Aneka Motor Jakarta dari tanggal 2 januari 2019 s/d 29 maret 2019. Sedangkan table 3 dibawah merupakan sample Format Tabular Data Transaksi

Tabel 3. Tabel Format Tabular Data Transaksi

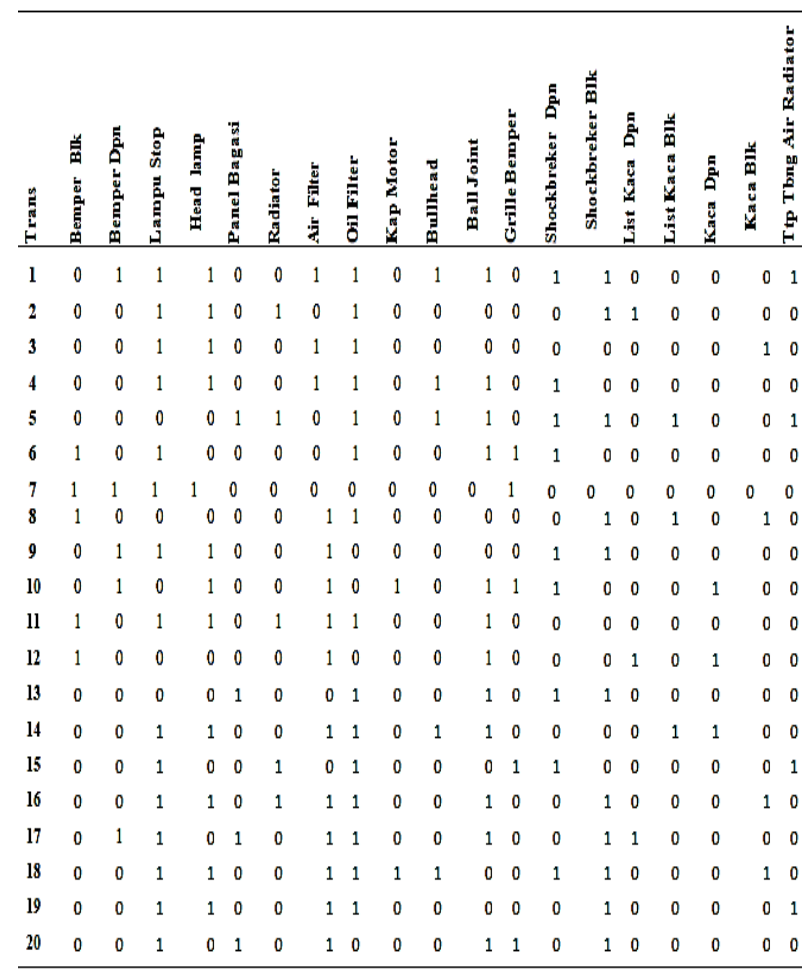


1. Pembentukan itemset

Berikut ini adalah penyelesaian dengan contoh kasus berdasarkan data yang sudah disediakan. Proses pembentukan $\mathrm{C}_{1}$ atau disebut dengan 1 itemset dengan jumlah minimun support $=25 \%$. Dengan rumus sebagai berikut (Nofriansyah, 2014):

$$
\text { Support }(A)=\frac{\sum \text { Transaksi mengandung } A}{\sum \text { Transakasi }} * 100 \%
$$

Tabel 4. Support Dari Setiap Itemset

\begin{tabular}{|c|c|c|}
\hline Nama Sparepart & Count & Support \\
\hline Bemper BLK & $101 / 286$ & $35,32 \%$ \\
\hline Bemper DPN & $97 / 286$ & $33,92 \%$ \\
\hline Lampu Stop & $180 / 286$ & $62,94 \%$ \\
\hline Headlamp & $113 / 286$ & $39,51 \%$ \\
\hline Panel Bagasi & $41 / 286$ & $14,36 \%$ \\
\hline Radiator & $116 / 286$ & $40,56 \%$ \\
\hline Air Filter & $143 / 286$ & $50 \%$ \\
\hline Oil Filter & $164 / 286$ & $57,35 \%$ \\
\hline Kap Motor & $49 / 286$ & $17,13 \%$ \\
\hline Bullhead & $30 / 286$ & $10,49 \%$ \\
\hline Balljoint & $100 / 286$ & $34,96 \%$ \\
\hline Grille Bemper & $37 / 286$ & $12,94 \%$ \\
\hline Shockbreker DPN & $90 / 286$ & $31,47 \%$ \\
\hline Shockbreker BLK & $92 / 286$ & $32,17 \%$ \\
\hline List Kaca DPN & $31 / 286$ & $10,84 \%$ \\
\hline List Kaca BLK & $35 / 286$ & $12,24 \%$ \\
\hline Kaca DPN & $39 / 286$ & $13,63 \%$ \\
\hline Kaca BLK & $37 / 286$ & $12,94 \%$ \\
\hline $\begin{array}{l}\text { Tutup Tabung Air } \\
\text { Radiator }\end{array}$ & $33 / 286$ & $11,54 \%$ \\
\hline
\end{tabular}

\section{2. kombinasi 2 itemset}

Proses pembentukan $\mathrm{C} 2$ atau disebut 2 itemset dengan jumlah minimum support $=25 \%$. Tabel 5 berikut menunjukkan kombinasi 2 itemset:

Table 5. Kombinasi 2 Itemset

\begin{tabular}{lll}
\hline Nama Sparepart & Count & Support \\
\hline Bemper BLK, Bemper & $32 / 286$ & $11,19 \%$ \\
DPN & & \\
Bemper BLK, Lampu & $62 / 286$ & $21,68 \%$ \\
Stop & & \\
Bemper BLK, Head Lamp & $38 / 286$ & $13,29 \%$ \\
Bemper BLK, Radiator & $27 / 286$ & $9,45 \%$ \\
Bemper BLK, Air Filter & $49 / 286$ & $17,14 \%$ \\
Bemper BLk, Oil Filter & $55 / 286$ & $19,24 \%$ \\
Bemper BLK, Balljoint & $33 / 286$ & $11,54 \%$ \\
Bemper BLK, & $29 / 286$ & $10,14 \%$ \\
Shockbreker DPN & & \\
\hline
\end{tabular}

\begin{tabular}{|c|c|c|}
\hline $\begin{array}{l}\text { Bemper BLK, } \\
\text { Shockbreker BLK }\end{array}$ & $26 / 286$ & $9,09 \%$ \\
\hline $\begin{array}{l}\text { Bemper DPN, Lampu } \\
\text { Stop }\end{array}$ & $65 / 286$ & $22,73 \%$ \\
\hline Bemper DPN, Headlamp & $36 / 286$ & $12,59 \%$ \\
\hline Bemper DPN, Radiator & $32 / 286$ & $11,19 \%$ \\
\hline Bemper DPN, Air Filter & $48 / 286$ & $16,78 \%$ \\
\hline Bemper DPN, Oil Filter & $55 / 286$ & $19,23 \%$ \\
\hline Bemper DPN, Balljont & $29 / 286$ & $10,14 \%$ \\
\hline $\begin{array}{l}\text { Bemper DPN, } \\
\text { Shockbreker DPN }\end{array}$ & $31 / 286$ & $10,84 \%$ \\
\hline $\begin{array}{l}\text { Bemper DPN, } \\
\text { Shockbreker BLk }\end{array}$ & $33 / 286$ & $11,54 \%$ \\
\hline Lampu Stop, Headlamp & $78 / 286$ & $27,27 \%$ \\
\hline Lampu Stop, Radiator & $75 / 286$ & $26,22 \%$ \\
\hline Lampu Stop, Air Filter & $77 / 286$ & $26,92 \%$ \\
\hline Lampu Stop, Oil Filter & $101 / 286$ & $35,32 \%$ \\
\hline Lampu Stop, Balljoint & $65 / 286$ & $22,72 \%$ \\
\hline $\begin{array}{l}\text { Lampu Stop, Shockbreker } \\
\text { DPN }\end{array}$ & $62 / 286$ & $21,68 \%$ \\
\hline $\begin{array}{l}\text { Lampu Stop, Shockbreker } \\
\text { BLK }\end{array}$ & $49 / 286$ & $17,13 \%$ \\
\hline Headlamp, Radiator & $48 / 286$ & $16,78 \%$ \\
\hline Headlamp, Air Filter & $51 / 286$ & $17,83 \%$ \\
\hline Headlamp, Oil Filter & $66 / 286$ & $23,08 \%$ \\
\hline Headlamp, Balljoint & $41 / 286$ & $14,34 \%$ \\
\hline $\begin{array}{l}\text { Headlamp, Shockbreker } \\
\text { DPN }\end{array}$ & $32 / 286$ & $11,19 \%$ \\
\hline $\begin{array}{l}\text { Headlamp, Shockbreker } \\
\text { BLK }\end{array}$ & $34 / 286$ & $11,89 \%$ \\
\hline Radiator, Air Filter & $52 / 286$ & $18,18 \%$ \\
\hline Radiator, Oil Filter & $66 / 286$ & $23,08 \%$ \\
\hline Radiator, Balljoint & $40 / 286$ & $13,99 \%$ \\
\hline $\begin{array}{l}\text { Radiator, Shockbreker } \\
\text { DPN }\end{array}$ & $33 / 286$ & $11,54 \%$ \\
\hline $\begin{array}{l}\text { Radiator, Shockbreker } \\
\text { BLK }\end{array}$ & $35 / 286$ & $12,24 \%$ \\
\hline Air Filter, Oil filter & $78 / 286$ & $27,27 \%$ \\
\hline Air Filter, Balljoint & $60 / 286$ & $20,98 \%$ \\
\hline $\begin{array}{l}\text { Air Filter, Shockbreker } \\
\text { DPN }\end{array}$ & $44 / 286$ & $15,38 \%$ \\
\hline $\begin{array}{l}\text { Air Filter, Shockbreker } \\
\text { BLK }\end{array}$ & $42 / 286$ & $14,68 \%$ \\
\hline Oil Filter, Balljoint & $53 / 286$ & $18,53 \%$ \\
\hline $\begin{array}{l}\text { Oil Filter, Shockbreker } \\
\text { DPN }\end{array}$ & $46 / 286$ & $16,08 \%$ \\
\hline $\begin{array}{l}\text { Oil Filter, Shockbreker } \\
\text { BLK }\end{array}$ & $57 / 286$ & $19,93 \%$ \\
\hline $\begin{array}{l}\text { Balljoint, Shockbreker } \\
\text { DPN }\end{array}$ & $31 / 286$ & $10,84 \%$ \\
\hline $\begin{array}{l}\text { Balljoint, Shockbreker } \\
\text { BLK }\end{array}$ & $30 / 286$ & $10,49 \%$ \\
\hline $\begin{array}{l}\text { Shockbreker DPN, } \\
\text { Shockbreker BLK }\end{array}$ & $35 / 286$ & $11,19 \%$ \\
\hline
\end{tabular}




\section{3. kombinasi 3 itemset}

Proses pembentukan $\mathrm{C} 3$ atau disebut dengan jumlah minimum support $=25 \%$, hasil perhitungan dapat dilihat pada table 6 berikut:

Tabel 6. Kombinasi 3 Itemset

\begin{tabular}{lcc}
\hline Nama Sparepart & Count & Support \\
\hline $\begin{array}{l}\text { Lampu Stop, Headlamp, } \\
\text { Radiator }\end{array}$ & $34 / 286$ & $11,89 \%$ \\
$\begin{array}{l}\text { Lampu Stop, Headlamp, } \\
\text { Air Filter }\end{array}$ & $33 / 286$ & $11,54 \%$ \\
$\begin{array}{l}\text { Lampu Stop, Headlamp, } \\
\text { Oil Filter }\end{array}$ & $45 / 286$ & $15,73 \%$ \\
$\begin{array}{l}\text { Lampu Stop, Radiator, } \\
\text { Air Filter }\end{array}$ & $28 / 286$ & $9,79 \%$ \\
$\begin{array}{l}\text { Lampu Stop, Radiator, } \\
\text { Oil Filter }\end{array}$ & $39 / 286$ & $13,64 \%$ \\
$\begin{array}{l}\text { Lampu Stop, Oil Filter, } \\
\text { Air Filter }\end{array}$ & $38 / 286$ & $13,29 \%$ \\
$\begin{array}{l}\text { Headlamp, Radiator, Air } \\
\text { Filter }\end{array}$ & $22 / 286$ & $7,69 \%$ \\
$\begin{array}{l}\text { Headlamp, Radiator, Oil } \\
\text { Filter }\end{array}$ & $24 / 286$ & $8,39 \%$ \\
$\begin{array}{l}\text { Radiator, Air Filter, Oil } \\
\text { Filter }\end{array}$ & $25 / 286$ & $8,74 \%$ \\
\hline
\end{tabular}

Karena kombinasi 3 itemset tidak ada yang memenuhi minimal support $25 \%$, maka kombinasi 2 itemset yang memenuhi untuk pembentukan asosiasi.

\section{Pembentukan Aturan Asosiasi}

Setelah semua pola frekuensi tinggi ditemukan, barulah dicari aturan asosiasi dengan hasil pola frekuensi yang ditunjukkan pada tabel 7 sebagai berikut:

Tabel 7. Hasil Pola Frekuensi Tinggi Yang Memenuhi Syarat

\begin{tabular}{|c|c|c|}
\hline Nama Sparepart & Count & Support \\
\hline Lampu Stop, Headlamp & $78 / 286$ & $27,27 \%$ \\
\hline Lampu Stop, Radiator & $75 / 286$ & $26,22 \%$ \\
\hline Lampu Stop, Air Filter & $77 / 286$ & $26,92 \%$ \\
\hline Lampu Stop, Oil Filter & $101 / 286$ & $35,32 \%$ \\
\hline Air Filter, Oil filter & $78 / 286$ & $27,27 \%$ \\
\hline
\end{tabular}

Setelah semua pola frekuensi tinggi ditemukan, barulah dicari aturan asosiasi yang memenuhi syarat minimum untuk confidence dengan menghitung confidence atau asosiasi $\mathrm{A} \rightarrow \mathrm{B}$, dengan minimum confidence $60 \%$.
Tabel 8. Hasil Final Asosiasi

\begin{tabular}{llc}
\hline \multicolumn{1}{c}{ Aturan } & \multicolumn{1}{c}{ Confidence } \\
\hline $\begin{array}{l}\text { Jika membeli lampu stop, maka } \\
\text { akan membeli headlamp }\end{array}$ & $78 / 180$ & $43,33 \%$ \\
$\begin{array}{l}\text { Jika membeli headlamp, maka } \\
\text { akan membeli lampu stop }\end{array}$ & $78 / 113$ & $69,03 \%$ \\
$\begin{array}{l}\text { Jika membeli lampu stop, maka } \\
\text { akan membeli radiator }\end{array}$ & $75 / 180$ & $41,67 \%$ \\
$\begin{array}{l}\text { Jika membeli radiator, maka akan } \\
\text { membeli lampu stop }\end{array}$ & $75 / 116$ & $64,65 \%$ \\
$\begin{array}{l}\text { Jika membeli lampu stop, maka } \\
\text { akan membeli air filter }\end{array}$ & $77 / 180$ & $42,78 \%$ \\
$\begin{array}{l}\text { Jika membeli air filter, maka akan } \\
\text { membeli lampu stop }\end{array}$ & $77 / 143$ & $53,85 \%$ \\
$\begin{array}{l}\text { Jika membeli lampu stop, maka } \\
\text { akan membeli oil filter }\end{array}$ & $101 / 180$ & $56,11 \%$ \\
$\begin{array}{l}\text { Jika membeli oil filter, maka akan } \\
\text { membeli lampu stop }\end{array}$ & $101 / 164$ & $61,58 \%$ \\
$\begin{array}{l}\text { jika membeli air filter, maka akan } \\
\text { membeli oil filter }\end{array}$ & $78 / 143$ & $54,55 \%$ \\
$\begin{array}{l}\text { jika membeli oil filter, maka akan } \\
\text { membeli air filter }\end{array}$ & $78 / 164$ & $47,56 \%$ \\
\hline
\end{tabular}

\section{Implementasi Algoritma Pada Rapidminer}

Setelah melakukan perhitungan manual, data transaksi penjualan tersebut dilakukan juga ujicoba menggunakan aplikasi Rapidminer, desain model Algoritma Apriori ditunjukkan pada gambar 2 berikut:

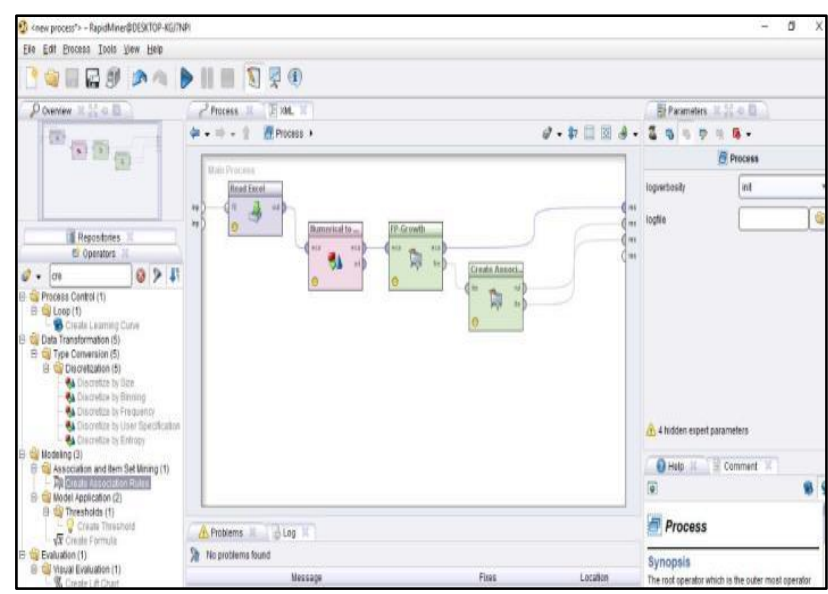

Gambar 2. Desain Model Algoritma Apriori menggunakan aplikasi Rapidminer

Tampilan Association Rules dan Frequent Item Set (FP-Growth) ditunjukkan pada gambar 3 berikut 


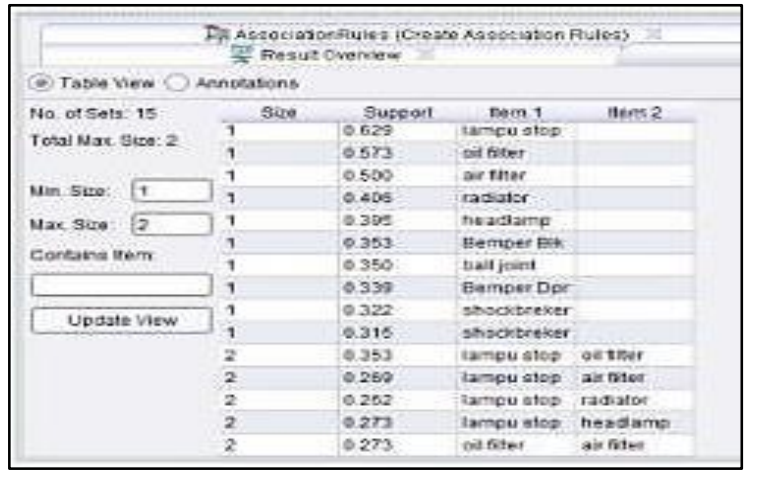

Gambar 3. Hasil FP-Growth pada Rapidminer 5.2

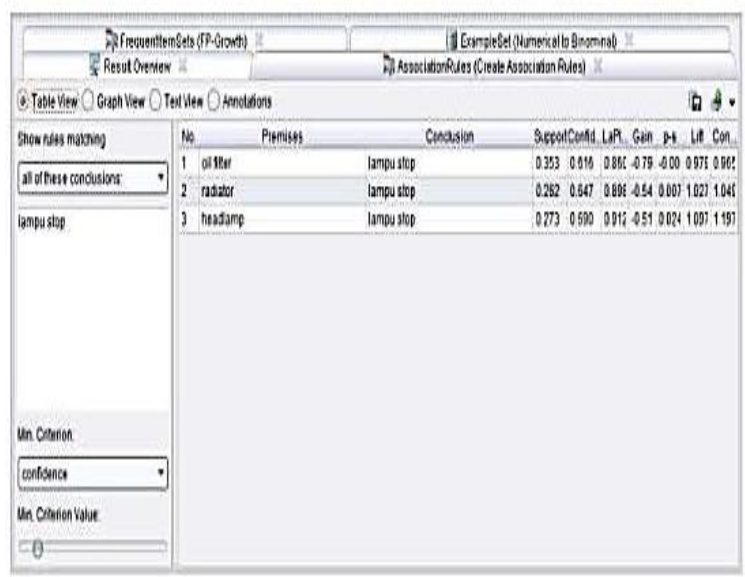

Gambar 4. Hasil Assosiation Rule pada Rapidminer 5.2

Gambar 4. Diatas merupakan hasil Assosiation Rule pada Rapidminer 5.2, sedangkan gambar 5 berikut menunjukkan tampilan Graph View Assosiation Rule:

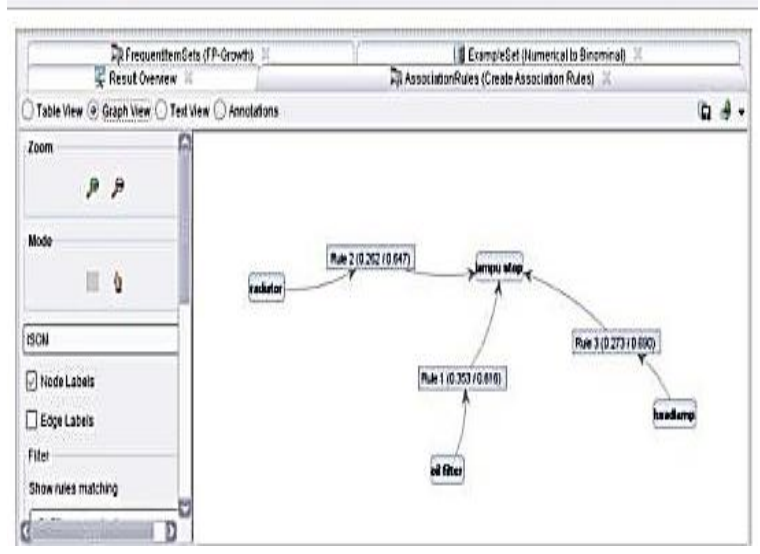

Gambar 5. Tampilan Graph View Assosiation Rule

Dari hasil support dan confidence yang terbesar adalah jika membeli radiator makan akan membeli lampu stop support 26,92\% dan confidence 64,65\%, jika membeli oil filter maka akan membeli lampu stop support 35,32\% dan confidence $61,58 \%$ dan jika membeli lampu stop maka akan membeli headlamp support $27,27 \%$ dan confidence $69,03 \%$.

\section{KESIMPULAN}

Tujuan dari penerapan Algoritma Apriori dalam penelitian ini adalah untuk mencari kombinasi item terbanyak berdasarkan data transaksi dan kemudian membentuk pola asosiasi dari kombinasi item tersebut. Pola asosiasi yang terbentuk dengan nilai minimum support $25 \%$ dan nilai minimum confidence $60 \%$ menghasilkan 3 aturan asosiasi yaitu radiator dengan lampu stop minimum support $26,92 \%$ sedangkan minimum confidence $64,65 \%$ dan oil filter dengan lampu stop minimum support $35,32 \%$ sedangkan minimum confidence $61,58 \%$ dan lampu stop dengan head lamp support $27,27 \%$, confidence $69,03 \%$. Menghasilkan aturan asosiatif atau pola transaksi konsumen. Sehingga dapat diketahui informasi produk apa saja yang sering muncul. Aturan kombinasi produk berhasil ditemukan dengan menggunakan association rules dan telah diuji menggunakan tools RapidMiner.

\section{REFERENSI}

Badrul, M. (2016). Algoritma asosiasi dengan algoritma apriori untuk analisa data penjualan. Jurnal Pilar Nusa Mandiri, XII(2), 121-129. https://ejournal.nusamandiri.ac.id/index.php/pi lar/article/view/266

Muflikhah, L., Ratnawati, dian eka, \& Putri, rekyan regasari mardi. (2018). Data Mining (Cetakan pe). UB Press. https://books.google.co.id/books?id=V_NqDw AAQBAJ\&printsec $=$ frontcover $\& \mathrm{dq}=\mathrm{data}+\mathrm{min}$ ing + Muflikhah\&hl=id\&sa=X\&ved=2ahUKE wj09qrzdvrAhWLX30KHWzBCCAQ6AEwAHoE CAEQAg\# $\mathrm{v}=$ onepage $\& \mathrm{q}=$ data mining Muflikhah\&f=false

Muhammad, Z., Rahmadhani, R., Rizqifaluthi, H., \& Yaqin, M. A. (2018). Process Mining Akademik Sekolah menggunakan RapidMiner. Matics, 10(2), 47-51. https://doi.org/10.18860/mat.v10i2.5158

Nofriansyah, D. (2014). Konsep Data Mining Vs Sistem Pendukung Keputusan. Deepublish.

Santoso, H., Hariyadi, I. P., \& Prayitno. (2016). Data Mining Analisa Pola Pembelian Produk. Seminar Nasional Teknologi Informasi Dan Multimedia 2016, 4(1), 19-24. http://ojs.amikom.ac.id/index.php/semnastekn omedia/article/download/1267/1200

Saputra, S. B. A., Dwiana, R., Oktaviani, W. D. N., Isnaeni, R. D., Astuti, T., \& Nurfaizah. (2016). Implementasi Data Mining Algoritme Apriori pada Penjualan Suku Cadang Motor Delta Motor. Citisee, 108-113.

Ummi, K. (2016). Nalisa Data Mining Dalam Penjualan Sparepart Mobil Dengan Menggunakan Metode Algoritma Apriori 
(Studi Kasus: Di Pt. Idk 1 Medan). CSRID

(Computer Science Research and Its

Development Journal), 8(3), 155-164. https://doi.org/10.22303/csrid.8.3.2016.155-

164

\section{PROFIL PENULIS}

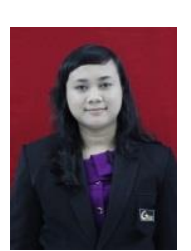

Penulis pertama Normah, memperoleh gelar M.Kom, Jurusan Ilmu Komputer pada STMIK Nusa Mandiri Jakarta, lulus tahun 2014. Saat ini menjadi Dosen di STMIK Nusa Mandiri (S1) program studi Teknik Informatika.

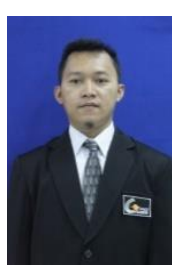

Penulis kedua Bakhtiar Rifai, memperoleh gelar M.Kom, Jurusan Ilmu Komputer pada STMIK Nusa Mandiri Jakarta, lulus tahun 2013. Saat ini menjadi Dosen di STMIK Nusa Mandiri (S1) program studi Teknik Informatika.

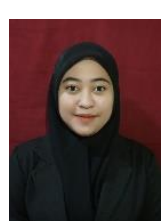

Penulis ketiga Pita Sari merupakan alumni STMIK Nusa mandiri program studi Sistem Informasi, lulus pada tahun 2019. 